\title{
Apparent Fracture Toughness of Pressureless Sintered Silver
}

\section{Interconnects}

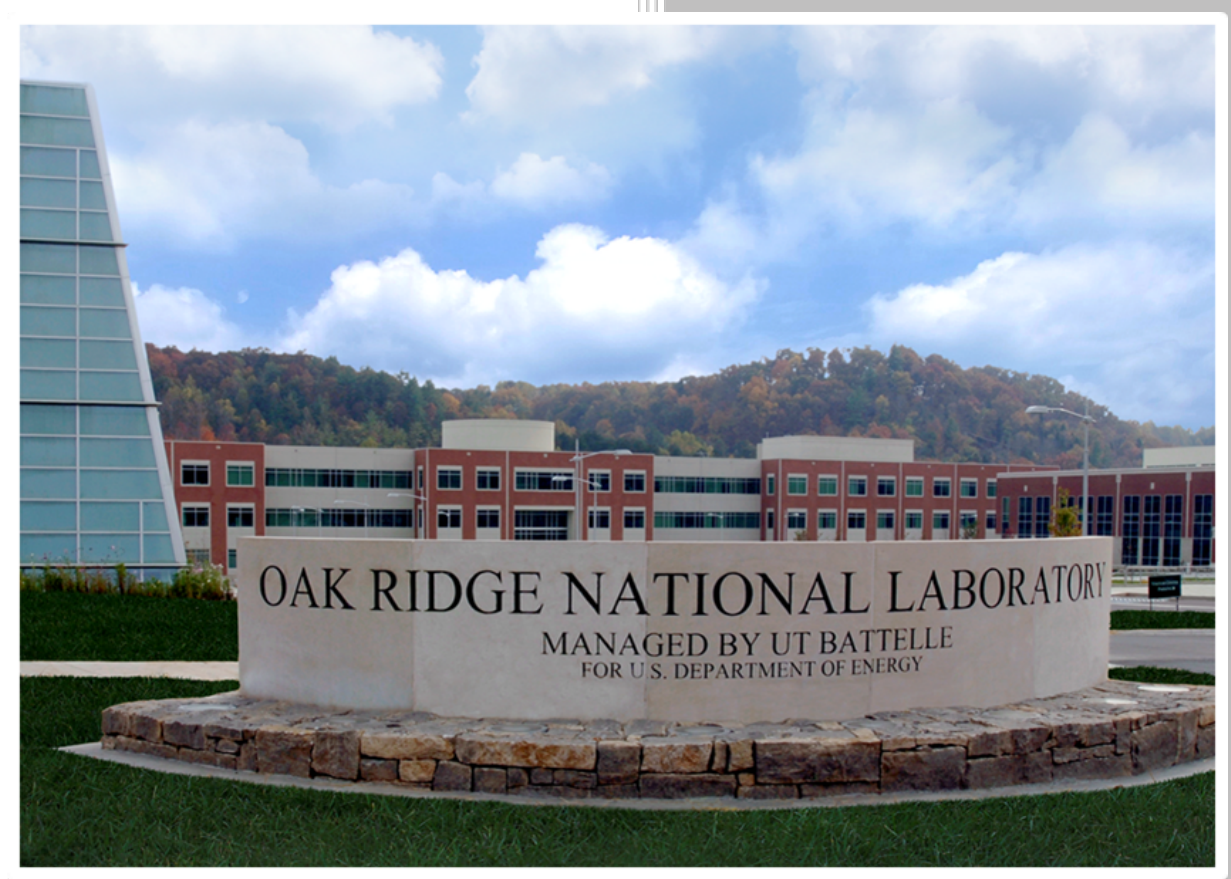

Approved for public release.

Distribution is unlimited.

Andrew A. Wereszczak

Max C. Modugno

Branndon R. Chen

Brian A. Oistad

June 2018 


\title{
DOCUMENT AVAILABILITY
}

Reports produced after January 1, 1996, are generally available free via US Department of Energy (DOE) SciTech Connect.

Website www.osti.gov

Reports produced before January 1, 1996, may be purchased by members of the public from the following source:

\author{
National Technical Information Service \\ 5285 Port Royal Road \\ Springfield, VA 22161 \\ Telephone 703-605-6000 (1-800-553-6847) \\ TDD 703-487-4639 \\ Fax 703-605-6900 \\ E-mail info@ntis.gov \\ Website http://classic.ntis.gov/
}

Reports are available to DOE employees, DOE contractors, Energy Technology Data Exchange representatives, and International Nuclear Information System representatives from the following source:

Office of Scientific and Technical Information

PO Box 62

Oak Ridge, TN 37831

Telephone 865-576-8401

Fax 865-576-5728

E-mail reports@osti.gov

Website http://www.osti.gov/contact.html

This report was prepared as an account of work sponsored by an agency of the United States Government. Neither the United States Government nor any agency thereof, nor any of their employees, makes any warranty, express or implied, or assumes any legal liability or responsibility for the accuracy, completeness, or usefulness of any information, apparatus, product, or process disclosed, or represents that its use would not infringe privately owned rights. Reference herein to any specific commercial product, process, or service by trade name, trademark, manufacturer, or otherwise, does not necessarily constitute or imply its endorsement, recommendation, or favoring by the United States Government or any agency thereof. The views and opinions of authors expressed herein do not necessarily state or reflect those of the United States Government or any agency thereof. 
Materials Science and Technology Division

\title{
APPARENT FRACTURE TOUGHNESS OF PRESSURELESS SINTERED SILVER INTERCONNECTS
}

\author{
Andrew A. Wereszczak \\ Max C. Modugno \\ Branndon R. Chen \\ Brian A. Oistad
}

June 2018

\author{
Prepared by \\ OAK RIDGE NATIONAL LABORATORY \\ Oak Ridge, TN 37831-6283 \\ managed by \\ UT-BATTELLE, LLC \\ for the \\ US DEPARTMENT OF ENERGY \\ under contract DE-AC05-00OR22725
}





\section{CONTENTS}

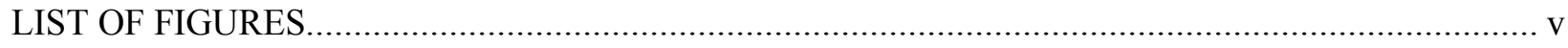

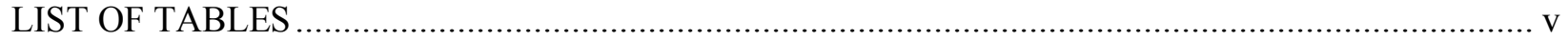

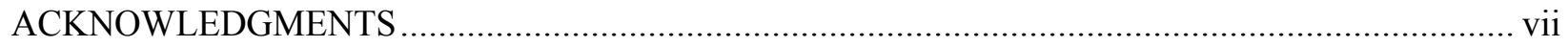

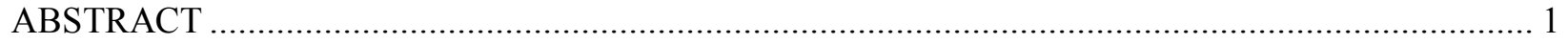

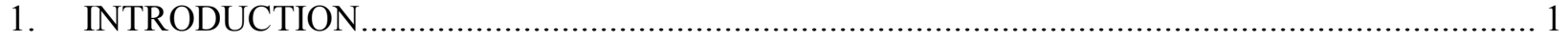

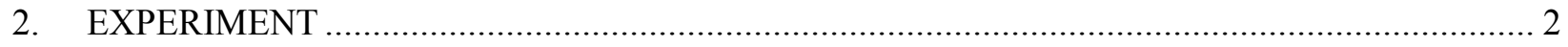

2.1 FABRICATION OF INTERCONNECT BEND TEST SPECIMENS (IBTS) ….................. 2

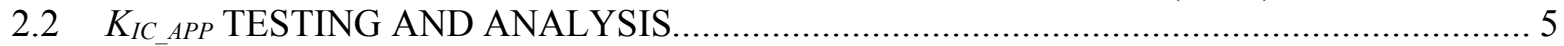

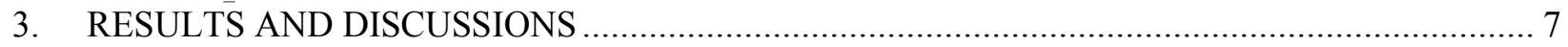

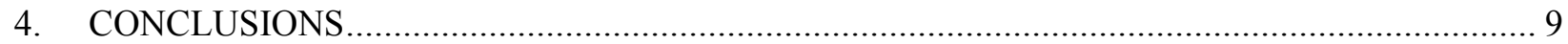

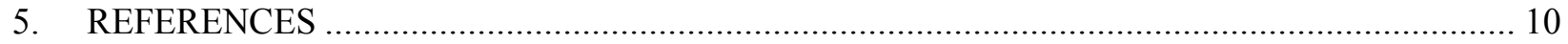





\section{LIST OF FIGURES}

Figure 1. Exploded view of the constituents comprising the interconnect bend test specimen.

Figure 2. Schematic of the printed chevron-shaped print on a square direct bonded copper substrate. The $\mathrm{Al}_{2} \mathrm{O}_{3}$ substrate is $12.7 \mathrm{~mm} \times 12.7 \mathrm{~mm}$, and $\mathrm{W}=\mathrm{B}=11.9 \mathrm{~mm}$ for the copper cladding. $\mathrm{a}_{\mathrm{o}}$ is the initial crack length of the chevron and the bonded area of the chevron is a relatively large $65 \mathrm{~mm}^{2}$.

Figure 3. Examples of the (top row) printed sinterable silver chevrons on the silver-plated DBC substrates. The bottom row of shown DBC substrates would be mated to them. The DBC substrate size was nominally $12.7 \mathrm{~mm}$ x $12.7 \mathrm{~mm}$.

Figure 4. An alignment fixture was used to assemble the interconnect bend test specimens.................... 5

Figure 5. Examples of fabricated interconnect bend test specimens............................................... 5

Figure 6. Image showing an interconnect bend test specimen positioned in the 3-point bend fixture.

Figure 7. Typical force-displacement response of an interconnect bend test specimen........................ 7

Figure 8. Examination of the failure surfaces showed the presence of processing defects and that adhesive failure typically occurred. The dashed arrows show the crack propagation direction.

\section{LIST OF TABLES}

Table 1. Comparison of apparent fracture toughness for a variety of interconnects and the employed test methods for their measurements. 



\section{ACKNOWLEDGMENTS}

Research co-sponsored by the Propulsion Materials Program and the Electric Drive Technologies Programs, DOE Vehicle Technologies Office, under contract DE-AC05-00OR22725 with UT-Battelle, LLC. The authors thank USDOE's J. Gibbs and S. Rogers, NASA-GRC's J. Salem and Fresno State's M. Jenkins for technical insights, ORNL's A. Haynes, B. Ozpineci, and M. Chinthavali for their financial and programmatic support, R. Parten for fabricating the interconnect bend test specimen assembly fixture, R. Wiles for CAD assistance, K. Jones for manuscript-formatting assistance, and V. Galigekere and E. Lara-Curzio for reviewing the manuscript. 



\begin{abstract}
This study uses three-point flexural testing to estimate the room-temperature apparent fracture toughness $\left(K_{\text {I_ app }}\right)$ of a pressureless sintered-silver interconnect - a candidate material for use in power electronic devices. The $K_{I c \_a p p}$ estimation occurs via work-of-fracture measurement of a chevron-shaped sinteredsilver joint centrally located in an "interconnect bend test specimen". The chevron-shape was stencilprinted on a silver (Ag)-plated direct bonded copper (DBC) substrate, mated to an Ag-plated DBC substrate, and then sintered. The chevron-shape, used for decades in fracture mechanics examinations and in standardized tests of monolithic materials, enables controlled stable crack initiation and propagation that are prerequisites for valid $K_{\text {Ic_app }}$ estimation. The employed combination of an interconnect bend test specimen and bend test method is robust and simple, enables a means for interpreting the resistance to crack growth and delamination in an interconnect, provides a dependable way to judge the efficacies of sintered-silver processing conditions, and ultimately supports process optimization of sintered-silver interconnects.
\end{abstract}

\title{
1. INTRODUCTION
}

Fracture toughness is a relevant mechanical property when considering crack propagation in a material. Fracture toughness's importance, measurement, and interpretation in materials science and engineering is well acknowledged by the very existence of several standardized tests for bulk or monolithic materials [13]. It is obviously desirable that crack initiation and subsequent propagation never occur in a component; however, if they do, then their understanding allows for their management and even enables an ability to predictably replace a component before it loses its expected functionality.

Interconnects in power electronic devices are relied upon for providing electrical and thermal (or heat transfer) functions. They (e.g., solders, brazes) are mostly used to bond semiconductors to substrates and substrates to base plates. The interconnects are formed at elevated temperatures and therefore experience residual stresses at all other temperatures, including those of device service, because they typically bond dissimilar materials having dissimilar coefficients-of-thermal-expansion and stiffness.

The high-aspect-ratioed geometry (i.e., thin and relatively large bond area) of a residually-stressed interconnect is typically under sustained in-plane shear and/or out-of-plane tension. If those residual stresses are sufficiently large or the material is susceptible to fatigue, or other non-equilibrium changesin-material state occur (or combinations thereof), then crack initiation and propagation will result. Such cracking reduces the interconnect's total bond area. That in turn increases the current density and also decreases the efficacy of thermal transfer in the interconnect, and their continued mutual propagation of one another can avalanche resulting in additional Joule heating and crack propagation and eventual device malfunction and failure. Therefore, understanding and measuring the fracture toughness of an interconnect material is quite important. The effects of residual stresses in interconnect systems are discussed further in prior mechanical testing studies [4].

Sintered-silver is an attractive candidate interconnect material for use in power electronic devices because of its high electrical and thermal conductivities and Restriction of Hazardous Substances (RoHS) compliance. There is a growing amount of literature on sintered-silver technology, including Siow's [5] thorough review; however, studies devoted to its mechanical properties and mechanical responses continue to be a small fraction of the total literature. Efforts of the present study's authors over the last several years have been associated with shear- and tensile-strength measurements [6-8], but the fracture toughness of sintered-silver interconnects has not been examined until this study. 
Before proceeding, the term "apparent fracture toughness" or $K_{I c-a p p}$ is purposely used in this study to describe the crack resistance response. This is because the use of "fracture toughness" $\left(K_{I c}\right)$, without inclusion of the adjective "apparent", would be erroneous and misleading. The $K_{I c-a p p}$ represents crack growth resistance in a material system, such as the interconnect system evaluated in this study, and is a material characteristic. However, $K_{I c}$ strictly is a property of a dense monolithic material. The $K_{I c-a p p}$ is relatable to $K_{I c}$ but their inter-dependence can be complex or even indeterminate. Additionally $K_{I c-a p p}$ can be dependent on the employed test method, test conditions, specimen geometry, sub-architectures or heterogeneous microstructures in the material, and residual stresses whereas $K_{I c}$ is independent of those. We are measuring $K_{I c-a p p}$ because we are studying the crack propagation response in a "sintered-silver interconnect system" where the system is comprised of the sintered-silver, the plating materials, and the substrates bonded to the silver, and because the crack response could also be affected by the sinteredsilver's porosity and the processing-induced residual stresses.

Here we use 3-pt-flexural testing to estimate the $K_{\text {Ic_app }}$ of a pressureless sintered silver interconnect. A work-of-fracture measurement is made with a chevron-shaped sintered-silver joint that is centrally located in an "interconnect bend test specimen". The chevron shape has been used for decades in fracture toughness testing of materials because it enables controlled stable crack initiation and propagation events that are prerequisites for valid fracture toughness testing and fracture toughness evaluation. The interconnect bend test specimen was simple to fabricate and mechanically test, and the resulting average $K_{\text {Ic app }}$ was found to be $1.5 \pm 0.2 \mathrm{MPa} \sqrt{\mathrm{m}}$ for the herein described pressureless sintered silver interconnect; specifically, that $K_{\text {Ic app }}$ was likely representative of the crack growth resistance of the interface between the sintered silver and the silver plating it was bonded to.

\section{EXPERIMENT}

A set of 20 interconnect bend test specimens were fabricated and subsequently flexure tested to determine an average $K_{\text {Ic_app }}$.

\subsection{FABRICATION OF INTERCONNECT BEND TEST SPECIMENS (IBTS)}

An exploded-view schematic of the IBTS is shown in Figure 1. Its fabrication was comprised of several steps.

\section{Silver chevron}

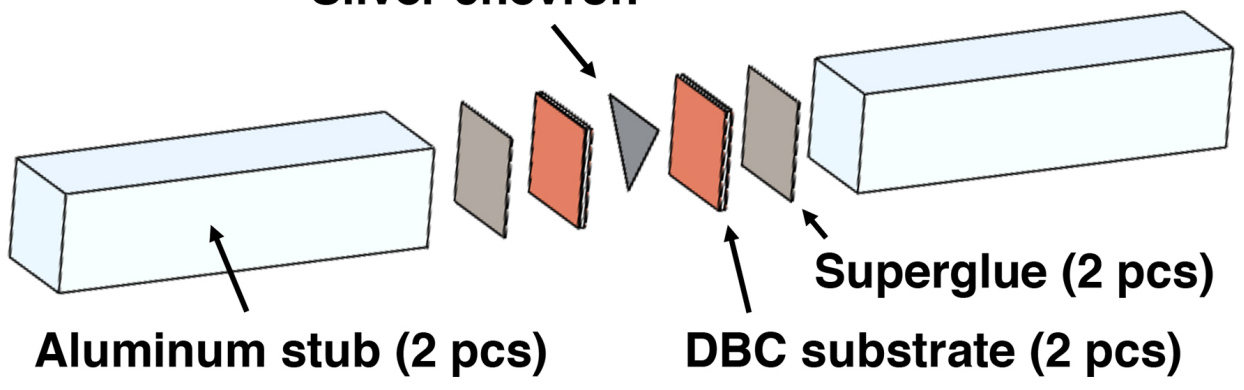

Figure 1. Exploded view of the constituents comprising the interconnect bend test specimen.

The first fabrication step was the stencil printing of the silver paste into a chevron-shape onto the plated surface of a direct bonded copper (DBC) substrate. The print shape is schematically shown in Figure 2 and examples of the printed chevrons are shown in Figure 3. The printed area of $65 \mathrm{~mm}^{2}$ is relatively large and would be, for example, an equivalent bond area to that for a $8 \mathrm{~mm} \times 8 \mathrm{~mm}$ semiconductor die in 
a power electronic device. A commercially available sinterable-silver paste* (Loctite Ablestik SSP 2020, Henkel Electronic Materials LLC, Irvine, CA) was used for the interconnect [9-10]. Its wet paste was printed using a stencil (UTZ Technologies, Little Falls, NJ) having a $0.102 \mathrm{~mm}$ thickness and chevronshape, as shown in Figure 2, onto DBC substrates that were comprised of 0.3-mm-thick x $11.9 \mathrm{~mm} \times 11.9$ $\mathrm{mm} \mathrm{Cu}$ cladding on a 0.6 -mm-thick x $12.7 \mathrm{~mm} \times 12.7 \mathrm{~mm}$ aluminum oxide ceramic substrate. The DBC substrate's $\mathrm{Cu}$ cladding was plated with electroless silver (approximately $4 \mu \mathrm{m}$ thick) by the substrate vendor (Remtec, Norwood, MA).

The DBC substrate sandwich with the sintered silver chevron-shape interconnect was formed next. An equivalently sized DBC substrate was placed on top of the printed chevron pad. An alignment fixture was used to keep the two mated DBC substrates aligned and parallel. A compressive stress of $\sim 4.3 \mathrm{kPa}$ was then applied for $5 \mathrm{sec}$ to set the DBC substrate surfaces against the printed silver paste. The authors of this study have confirmed previously that bonding is achievable with the stated procedure [11-12]. Twenty DBC substrate sandwiches were fabricated.

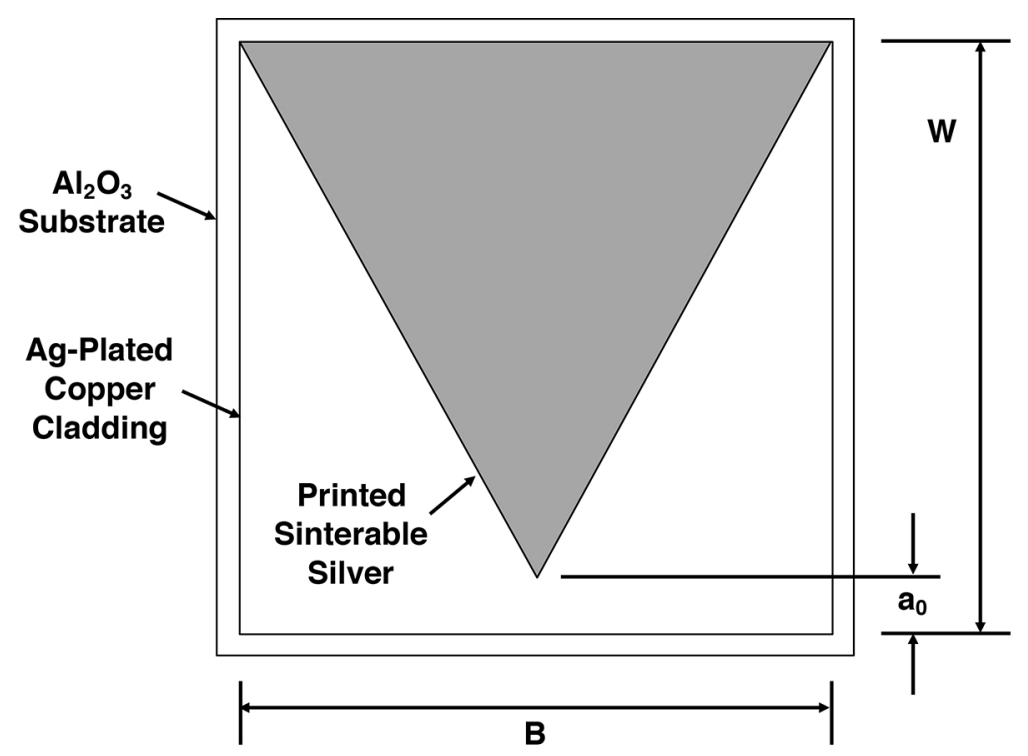

Figure 2. Schematic of the printed chevron-shaped print on a square direct bonded copper substrate. The $\mathrm{Al}_{2} \mathrm{O}_{3}$ substrate is $12.7 \mathrm{~mm} \times 12.7 \mathrm{~mm}$, and $\mathrm{W}=\mathrm{B}=11.9 \mathrm{~mm}$ for the copper cladding. $\mathrm{a}_{0}$ is the initial crack length of the chevron and the bonded area of the chevron is a relatively large $65 \mathrm{~mm}^{2}$.

\footnotetext{
${ }^{*}$ Certain commercial materials and equipment and their manufacturers are identified to adequately describe the experimental procedure. This does not imply their endorsement by the Oak Ridge National Laboratory, UT-Battelle, US Department of Energy, and Oak Ridge Associated Universities, nor its employees, nor that they are necessarily the best or only choices for these purposes.
} 


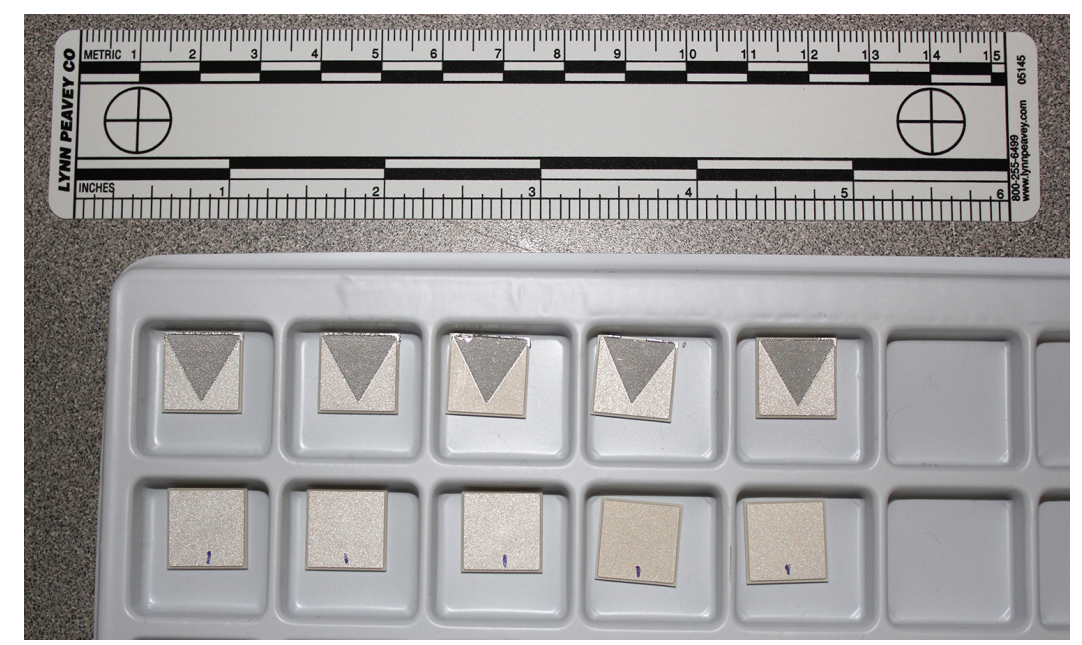

Figure 3. Examples of the (top row) printed sinterable silver chevrons on the silver-plated DBC substrates. The bottom row of shown DBC substrates would be mated to them. The DBC substrate size was nominally $12.7 \mathrm{~mm}$ $\mathrm{x} 12.7 \mathrm{~mm}$.

Pressureless sintering of the DBC substrate sandwiches containing the silver interconnects was conducted using the following thermal profile in an oven (Series 3600 oven, Applied Test Systems, Butler, PA):

i. $\quad 25^{\circ} \mathrm{C}$ to $75^{\circ} \mathrm{C}$ at $10^{\circ} \mathrm{C} / \mathrm{min}$,

ii. dwell at $75^{\circ} \mathrm{C}$ for $60 \mathrm{~min}$,

iii. $\quad 75^{\circ} \mathrm{C}$ to $250^{\circ} \mathrm{C}$ at $10^{\circ} \mathrm{C} / \mathrm{min}$,

iv. dwell at $250^{\circ} \mathrm{C}$ for $60 \mathrm{~min}$, and

v. natural cooling from $250^{\circ} \mathrm{C}$ to $25^{\circ} \mathrm{C}$.

Paste composition and thermal profile were designed such that oxidation is avoided at $250^{\circ} \mathrm{C}$, even in atmospheric conditions. The $75^{\circ} \mathrm{C}$-dwell-segment was used to promote the removal of the silver paste's solvent [11]. The above procedures produced a final sintered-silver interconnect thickness of approximately $100 \mu \mathrm{m}$. The plating thicknesses on the two DBC substrates added approximately $8 \mu \mathrm{m}$ to the total "interconnect system" thickness (or the distance between DBC substrate sandwich's innermost copper claddings).

Each DBC substrate sandwich was then glued (Loctite Ultra Gel Super Glue, Henkel Electronic Materials LLC, Irvine, CA) between two $12 \mathrm{~mm}$ x $12 \mathrm{~mm}$ x $50 \mathrm{~mm} 6061$ aluminum (Al) bars to fabricate an IBTS. This is shown in Figure 4. The bonded aluminum bars enabled the use of a desirably large span for the three-point bend testing. Examples of fabricated IBTS's are shown in Figure 5. The use of this glue accommodated room-temperature testing; however, the use of a higher-temperature-capable glue would in turn enable the measurement of apparent fracture toughness at higher-temperatures.

Connecting the Al bars to the DBC substrate sandwiches involved several steps. First, the Ag-plating was removed from the DBC substrates using a fine grit (400 grit) silicon carbide (SiC) grinding paper.

Previous studies by Modugno et al. [8] showed that the Ag-plating on these DBC substrates tends to fail before the silver interconnect, so it was desirable to avoid failure occurring at that copper-cladding-Agplating interface and to improve bonding with the glue. Next, a coarse (60 grit) SiC grinding paper was then used to add roughness to the ends of the Al bars to improve bonding to the glue. Lastly, all mating surfaces were cleaned with ethanol prior to their gluing. Care was used to ensure excess glue did not squeeze out and enter into the sintered-silver interconnect region. 


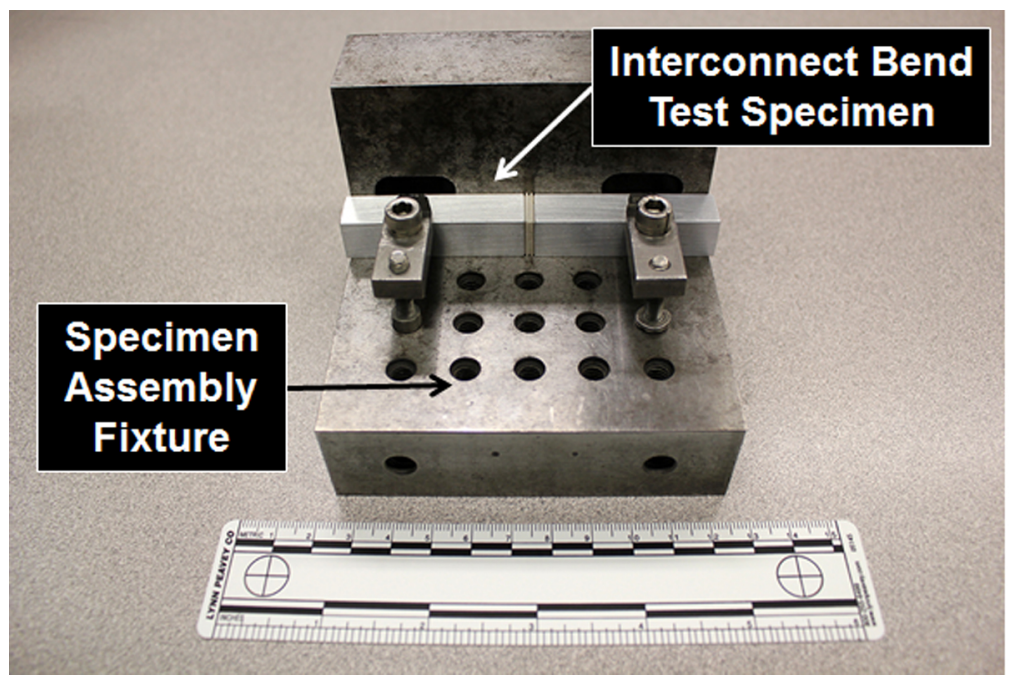

Figure 4. An alignment fixture was used to assemble the interconnect bend test specimens.

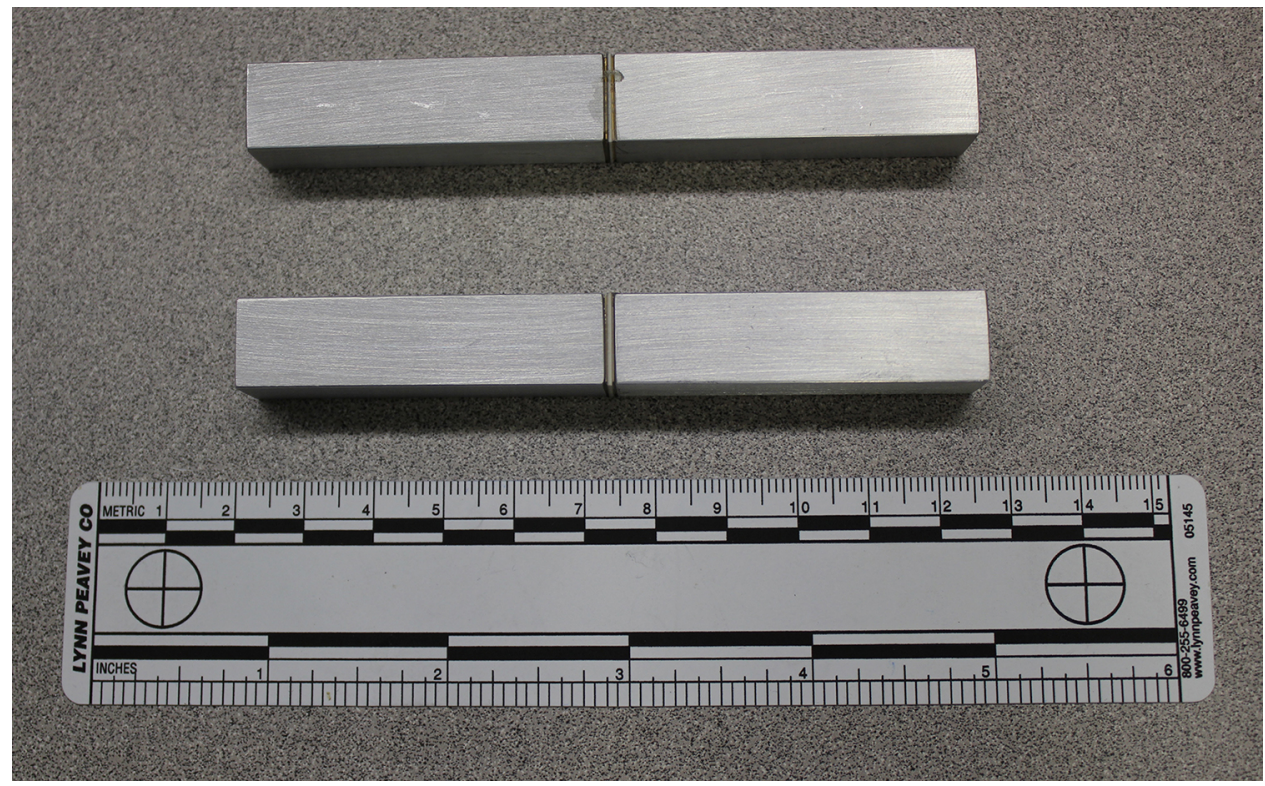

Figure 5. Examples of fabricated interconnect bend test specimens.

\section{2 $K_{I C \_A P P}$ TESTING AND ANALYSIS}

Mechanical testing was performed using 3-point bending with a universal test machine (Model 5867, Instron Corporation, Canton, MA). The test configuration is shown in Figure 6. The bottom span was 90 $\mathrm{mm}$. A displacement rate of $0.1 \mathrm{~mm} / \mathrm{min}$ was used and each test had a duration of 2-3 minutes. A slit slightly wider than the DBC sandwich was cut into the upper roller to put it in direct contact with the two Al bars and to avoid contact-induced failure initiation (an event that could have occurred if the roller came in direct contact with the two DBC substrates or loaded between them). A test was deemed valid if there was (i) a compliance increase, or slope decrease, that occurred in the load-displacement curve before attainment of maximum load, (ii) maximum in the load, and (iii) some load was sustained at displacements beyond where the maximum load was achieved [3]. 
The applied force $(P)$ was continually measured as a function of displacement $(U)$ for each IBTS and it was numerically integrated $(/ P d U)$ using the trapezoidal rule in a spreadsheet. The work-of-fracture $\left(\gamma_{\text {wof }}\right)$ was then estimated using [13-15]

$$
\gamma_{w o f}=\frac{\int P d U}{2 \cdot A}
$$

where $\mathrm{A}$ is the area of the sintered-silver's chevron shape $\left(65 \mathrm{~mm}^{2}\right.$ as shown in Figure 2$)$, and the numeral 2 is in the denominator because the fracture event created two surfaces.

The Mode I apparent fracture toughness $\left(K_{I C \_a p p}\right)$ was then calculated according to

$$
K_{I C_{-} a p p}=\sqrt{2 \cdot E \bullet \gamma_{w o f}},
$$

where $E$ is the elastic modulus of the sintered silver. The basis of Eq. 2 comes from the first law of thermodynamics [16]. The conventional MKS units of Mode I apparent fracture toughness are MPa $\sqrt{\mathrm{m}}$.

The E in Eq. 2 was estimated using a combination of experiment with monolithic, chevron-notched sintered silver specimens and finite element analysis, FEA, (ANSYS, Canonsburg, PA). The linear portion of the measured load-displacement of this 3-pt-loaded specimen was correlated to potential combinations of $E$ and Poisson's ratio $(v)$ of the FEA-modelled chevron-notched specimen. Paired E - $v$ combinations of $28.5 \mathrm{GPa}-0.1$ or $28.2 \mathrm{GPa}-0.2$ or $27.8 \mathrm{GPa}-0.3$ all satisfied that measured loaddisplacement response (i.e., there is not a unique paired solution). It was evident that Poisson's ratio did not have a significant influence on the E, so a value of $28 \mathrm{GPa}$ was thereafter used in Eq. 2's estimations of $K_{I c \_a p p}$. An E $=28 \mathrm{GPa}$, from such a mechanical loading, is consistent with a sonically-measured E for $\sim 75 \%$ dense monolithic sintered silver [7]. The apparent bulk density of the two monolithic bars was estimated using Archimedes' Principle and was $\sim 80 \%$ of silver's theoretical density $\left(10.5 \mathrm{~g} / \mathrm{cm}^{3}\right)$; this value is equivalent to $75 \%$ given the uncertainties of both the mechanically- and sonically-measured $\mathrm{E}$ values, and the uncertainty associated with using a sonic method to estimate the $\mathrm{E}$ of a porous material [17].

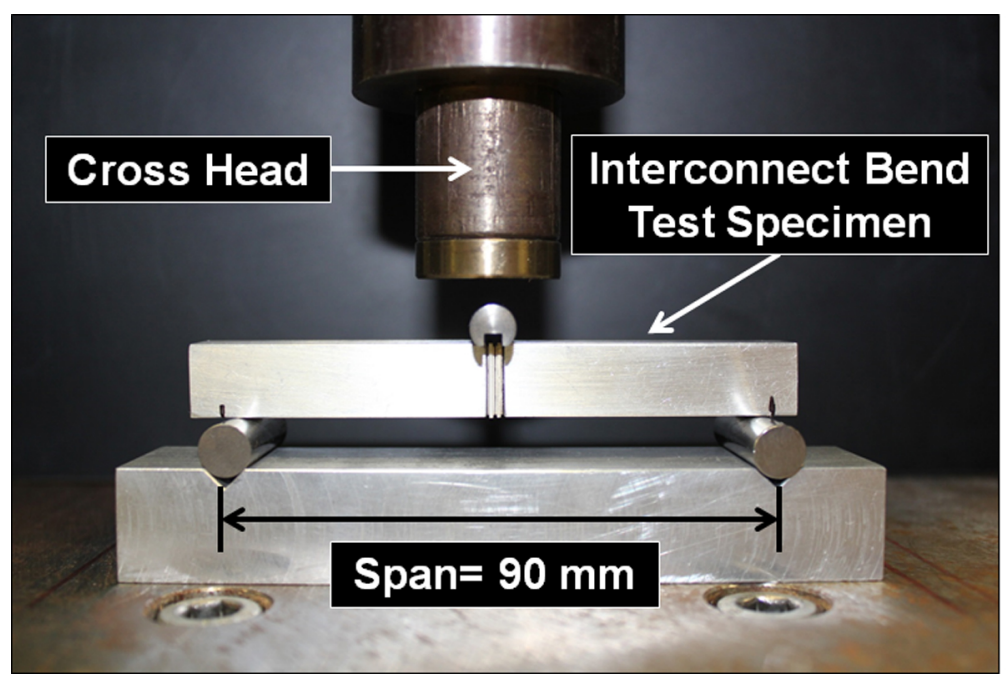

Figure 6. Image showing an interconnect bend test specimen positioned in the 3-point bend fixture. 


\section{RESULTS AND DISCUSSIONS}

All of the tests produced a valid test response illustrating the employed method's robustness and resulting confidence in the estimated $K_{I C_{-} a p p}$ values for the sintered silver interconnect. An example of an experimental load-displacement curve is shown in Figure 7 for one of the tests. There was sustained load after the load maxima illustrating stable crack propagation. The estimation of the work-of-fracture, and subsequent utilizations of Eqs. 1-2 to calculate $K_{I c \_a p p}$ then confidently proceeded.

The pressureless sintered-silver interconnect had an average $K_{\text {Ic_app }}$ of about $1.5 \mathrm{MPa} \sqrt{\mathrm{m}}$ and a standard deviation of $0.2 \mathrm{MPa} \sqrt{\mathrm{m}}$ for the 20 IBTS's.

This measured $K_{\text {Ic_app }}$ is essentially a measure of the crack growth resistance of the weakest location in the sintered silver interconnect "system". In these tested IBTS's, adhesive failure occurred at the bonding interface between the chevron-shaped sintered silver and the silver-plating on the DBC substrates. In this case, the measured $K_{\text {Ic_app }}$ of the interconnect is not limited by the (tougher) sintered silver's bulk or cohesive $K_{\text {Ic_app }}$. This difference is illustrated by the $K_{\text {Ic_app }}$ of monolithic sintered silver (2.3-2.4 MPa $\sqrt{\mathrm{m}}$ measured with two specimens in the present study); namely, the $K_{\text {Ic_app }}$ of the adhesive bond between the sintered silver and the DBC substrates silver plating would need to be $>2.3-2.4 \mathrm{MPa} \sqrt{\mathrm{m}}$ in order for crack propagation to instead have occurred within the sintered silver layer itself. The use of another plating material or plating strategy or both, that would have higher adhesive strength with the sintered silver, would increase the $K_{\text {Ic a } a p p}$ of the interconnect. That, in tandem with further optimization of the sintered silver processing so to eliminate processing defects like those shown in Figure 8, would also increase the overall $K_{\text {I__app }}$ of both the bulk sintered silver and the interconnect too.

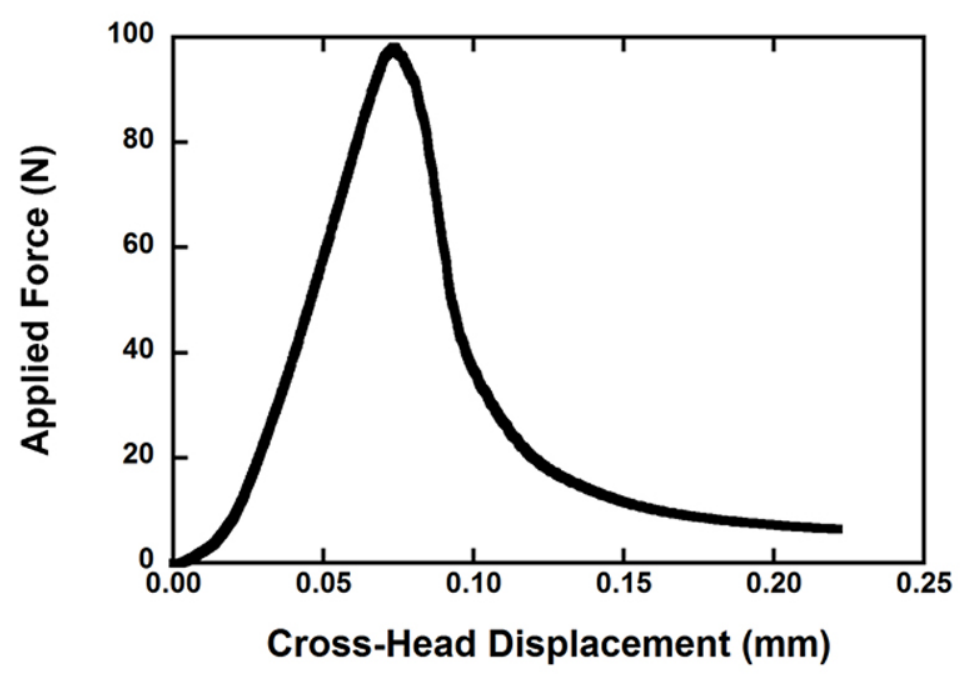

Figure 7. Typical force-displacement response of an interconnect bend test specimen. 


\section{Example of Mating Fracture Surfaces}

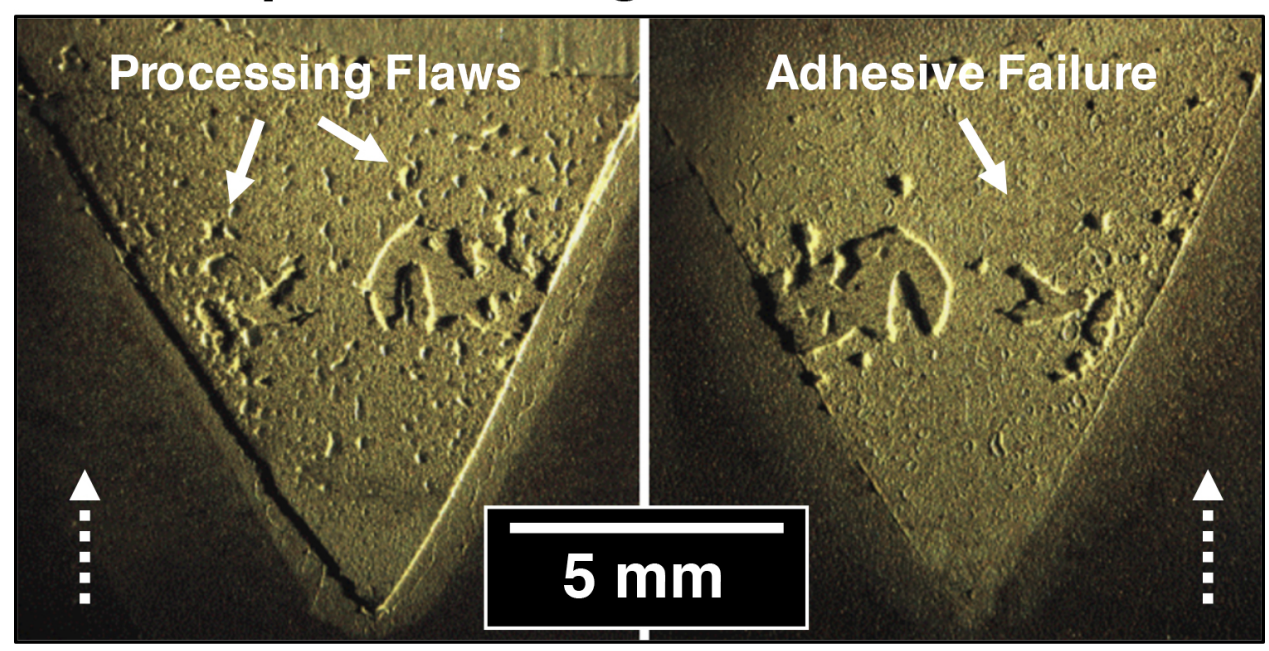

Figure 8. Examination of the failure surfaces showed the presence of processing defects and that adhesive failure typically occurred. The dashed arrows show the crack propagation direction.

A comparison of the $K_{\text {Ic_app }}$ of this study's sintered silver interconnects, that for monolithic sintered silver, and those for a variety of solders and brazing materials are shown in Table 1. An automated and more optimized process for sinterable silver and its interconnection would result it in being more equivalent to the $K_{I c \_a p p}$ of the other materials listed Table 1.

A variety of other fracture toughness test methods have been used to study crack growth resistance in other interconnect materials (as listed in Table 1); however, the herein described 3-point flexural test method of a chevron-shape-interconnect offers some advantages and enables an ability to more simply monitor the effects of interconnect processing conditions and to ultimately optimize them. Three-ptflexure is preferred here over 4-pt-flexure because there is less machine and fixture compliances and lessimposed roller friction. Those attributes, in addition to the use of a relatively large bottom span, results in low imposition of stored energy in the specimen during testing, which in turn increases the likelihood that both stable crack initiation and propagation occur (prerequisites for valid $K_{\text {Ic_app }}$ measurement). The single edge notch beam requires pre-cracking to form a starter crack, and that procedure often involves trial-anderror with a less than $100 \%$ success rate of valid testing. Compact tension testing of an interconnect requires the use of special tensile grips and a crack-tip opening displacement sensor; equipment that many laboratories do not have. 
Table 1. Comparison of apparent fracture toughness for a variety of interconnects and the employed test methods for their measurements.

\begin{tabular}{|c|c|c|c|}
\hline Interconnect Material & $\begin{array}{c}\text { Apparent Mode I } \\
\text { Fracture Toughness } \\
(\mathrm{MPa} \sqrt{ } \mathrm{m})\end{array}$ & Test Method and Specimen & Reference \\
\hline \multirow[t]{2}{*}{ Sintered silver } & $\begin{array}{c}\text { Ave. }=1.5 \\
\text { Std. Dev. }=0.2\end{array}$ & $\begin{array}{l}\text { 3-pt-bending, chevron-shape } \\
\text { joint formed with printing }\end{array}$ & This study \\
\hline & $2.3-2.4$ & $\begin{array}{l}\text { 3-pt-bending, chevron-notched } \\
\text { monolithic specimens }\end{array}$ & \\
\hline Brazing Ag-Cu-0.5Ti & $3-5$ & $\begin{array}{l}\text { 3-pt-bending, single edge notch } \\
\text { beam }\end{array}$ & [18] \\
\hline Solder $\mathrm{Sn}-\mathrm{Pb}$ & 8.36 & $\begin{array}{l}\text { Compact tension, chevron-shape } \\
\text { joint formed with masking }\end{array}$ & [19] \\
\hline Solder $96.5 \mathrm{Sn}-3.5 \mathrm{Ag}$ & $4.7-11$ & $\begin{array}{l}\text { 4-pt-bending, chevron-shape } \\
\text { joint formed with masking }\end{array}$ & [20] \\
\hline $\begin{array}{l}\text { Solder } 63 \mathrm{Sn}-37 \mathrm{~Pb} \\
\text { intermetallicized }\end{array}$ & $3-12$ & $\begin{array}{l}\text { 4-pt-bending, chevron-shape } \\
\text { joint formed with masking }\end{array}$ & [21] \\
\hline Solder $\mathrm{Pb}-\mathrm{Sn}$ and $\mathrm{Sn}-\mathrm{Ag}$ & $1-4.5$ & Compact tension, straight notch & {$[22]$} \\
\hline $\begin{array}{l}\text { Solder } \mathrm{Sn}-0.7 \mathrm{Cu} \text { and } \\
\text { Sn-4.0Ag-0.5Cu } \\
\text { intermetallicized }\end{array}$ & $5-9$ & Compact tension, straight notch & [23] \\
\hline Intermetallics $\mathrm{Sn}-\mathrm{Ag}-\mathrm{Cu}$ & $1.5-2.2$ & $\begin{array}{l}\text { 4-pt-bending, single edge notch } \\
\text { beam }\end{array}$ & [24] \\
\hline Solder Sn-3.8Ag-0.7Cu & $\begin{array}{l}\mathrm{G}_{\text {Ic }}=40-84 \mathrm{~J} / \mathrm{m}^{2} \\
\left(K_{\text {Ic }} \text { unreported }\right)\end{array}$ & Compact tension, straight notch & {$[25]$} \\
\hline
\end{tabular}

\section{CONCLUSIONS}

Pressureless sintered-silver interconnects had an average apparent fracture toughness of about $1.5 \pm 0.2 \mathrm{MPa} \sqrt{\mathrm{m}}$ at $25^{\circ} \mathrm{C}$. Failure appears to have occurred at the interface between the sintered-silver and silver plating on the DBC substrates. Automated and more optimized processing, and the use of a different plating strategy (that promoted better adherence to sintered-silver), would likely increase the measured apparent fracture toughness.

The employed test method enabled the valid estimation of apparent fracture toughness of a sintered-silver interconnect "system". That claimed validity is based on demonstrated (100\%) achievement of prerequisite stable crack growth needed for fracture toughness testing such as described in standardized testing of monolithic materials (i.e., ASTM C1421, E304, and E399 test standards). The analysis using work-of-fracture represents a simple approach, and the printing of sinterable silver directly onto relevant plated-substrates enables the study of crack growth resistance of a representative and entire interconnect system.

Three-point-bending of chevron-shaped interconnects, using the herein described procedures, desirably minimizes the introduction of machine and fixture compliance and maximizes the likelihood that cracking is stably initiated and propagated. Because of this test robustness, changes or trends in apparent fracture toughness from processing imperfections, non-automation, dissimilarity in plating technologies are interpretable without complications or false-positives introduced from testing-induced parasitics. 
The described method offers a simple and defendable means of interpreting the resistance to crack growth and delamination for sintered-silver interconnects resulting in the ability to monitor the effect of processing conditions and ultimately optimize them.

\section{REFERENCES}

[1] "Standard Test Method for Linear-Elastic Plane-Strain Fracture Toughness $\mathrm{K}_{\mathrm{Ic}}$ of Metallic Materials,” ASTM E399, ASTM International, West Conshohocken, PA (2012).

[2] "Standard Test Method for Plane-Strain (Chevron-Notch) Fracture Toughness of Metallic Materials," ASTM E1304, ASTM International, West Conshohocken, PA (2014).

[3] "Standard Test Methods for Determination of Fracture Toughness of Advanced Ceramics at Ambient Temperature," ASTM C1421, ASTM International, West Conshohocken, PA (2016).

[4] A. A. Wereszczak, B. R. Chen, O. M. Jadaan, B. A. Oistad, M. C. Modugno, J. W. Sharp, and J. R. Salvador, "Cantilever Testing of Sintered-Silver Interconnects," Journal of Materials Science; Materials in Electronics, 29:1530-1541 (2018).

[5] K. S. Siow, "Are Sintered Silver Joints Ready for Use as Interconnect Material in Microelectronic Packaging?” Journal of Electronic Materials, 43:947-961 (2014).

[6] A. A. Wereszczak, D. J. Vuono, Z. Liang, and E. E. Fox, "Sintered Silver Joint Strength Dependence on Substrate Topography and Attachment Pad Geometry," Paper 12.4 in 7th International Conference on Integrated Power Electronics Systems (CIPS), Nuremburg, Germany, March 6-8, 2012.

[7] A. A. Wereszczak, Z. Liang, M. K. Ferber, and L. D. Marlino, "Uniqueness and Challenges of Sintered Silver as a Bonded Interface Material," Journal of Microelectronics and Electronic Packaging, 11:158-165 (2014).

[8] M. C. Modugno, A. A. Wereszczak, and S. B. Waters, "Toward Interpreting Failure in SinteredSilver Interconnection Systems," pp. 234-241 in IMAPS HiTEC 2016, Paper WP26, Albuquerque, NM, 2016.

[9] LOCTITE ABLESTIK SSP 2020, Henkel Corporation, Technical Data Sheet, December 2012.

[10] LOCTITE ABLESTIK SSP 2020, Henkel Corporation, Safety Data Sheet, October 2014.

[11] A. A., Wereszczak, M. C., Modugno, B. R., Chen, and W. M., Carty, "Contact Drying of Printed Sinterable-Silver Paste," IEEE Transactions on Components, Packaging and Manufacturing Technology, 7:2079-2086 (2017).

[12] A. A., Wereszczak, B. R., Chen, B. A. Oistad, "Reflow-Oven-Processing of Pressureless SinteredSilver Interconnects," Journal of Materials Processing Technology, 255:500-506 (2018).

[13] J. Nakayama, "A Bending Method for Direct Measurement of Fracture Energy of Brittle Material," Japanese Journal of Applied Physics, 3:422-423 (1964).

[14] J. Nakayama, "Direct Measurement of Fracture Energies of Brittle Heterogeneous Materials," Journal of the American Ceramic Society, 48:583-587 (1965).

[15] H. G. Tattersall and G. Tappin, "The Work of Fracture and its Measurement in Metals, Ceramics and other Materials," Journal of Materials Science, 1:296-301 (1966).

[16] A. Kelly and N. H. Macmillan, Strong Solids, Third Edition, Clarendon Press, Oxford (1986). 
[17] A. A. Wereszczak, E. E Fox, M. J. Lance, and M. K. Ferber, "Failure Stress and Apparent Elastic Modulus of Diesel Particulate Filter Ceramics," SAE International Journal of Materials and Manufacturing, 5:517-527 (2012).

[18] H. C. Cho and J. Yu, "Effects of Brazing Temperature on the Fracture Toughness of Al2O3/Ag-Cu0.5Ti Joints," Scripta Metallurgica et Materilia, 26:797-802 (1992).

[19] R. E. Pratt, E. I. Stromswold, and D. J. Quesnel, "Mode I Fracture Toughness Testing of Eutectic Sn-Pb Solder Joints," Journal of Electronic Materials, 23:375-381 (1994).

[20] E. I. Stromswold, R. E. Pratt, and D. J. Quesnel, "The Effect of Substrate Surface Roughness on the Fracture Toughness of Cu/96.5Sn-3.5Ag Solder Joints," Journal of Electronic Materials, 23:10471053 (1994).

[21] R. E. Pratt, E. I. Stromswold, and D. J. Quesnel, "Effect of Solid-State Intermetallic Growth on the Fracture Toughness of $\mathrm{Cu} / 63 \mathrm{Sn}-37-\mathrm{Pb}$ Solder Joints," IEEE Transactions on Components, Packaging and Manufacturing Technology - Part A, 19:134-141 (1996).

[22] K. S. Siow and M. Manoharan, "Mixed mode fracture toughness of lead-tin and tin-silver solder joints with nickel-plated substrate," Materials Science and Engineering A, 404:244-250 (2005).

[23] K. S. Siow and M. Manoharan, "Interfacial fracture toughness of Pb-free solders," Microelectronics Reliability, 49:269-287 (2009).

[24] L. Ladani and J. Razmi, "Mechanical Strength and Failure Characterization of Sn-Ag-Cu Intermetallic Compound Joints at the Microscale," Journal of Electronic Materials, 41:573-579 (2012).

[25] Z. Huang, P. Kumar, I. Dutta, R. Sidhu, M. Renavikar, and R. Mahajan, "Effects of Microstructure and Loading on Fracture of Sn-3.8Ag-0.7Cu Joints on Cu Substrates with ENIG Surface Finish," Journal of Electronic Materials, 43:4485-4496 (2014). 
